\title{
Analysis of Tackling Events Leading to Mild Cervical Injuries in Collegiate Rugby Union
}

\author{
Keita Suzuki ${ }^{1 *}$, Satoshi Nagai ${ }^{2}$, Koichi Iwai ${ }^{1}$, Ryo Ogaki ${ }^{3}$, Takuo Furukawa ${ }^{4}$ and Masahiro Takemura ${ }^{4}$ \\ ${ }^{1}$ Center of Humanities and Sciences, Ibaraki Prefectural University of Health Sciences, 4669-2 Ami, Inashiki, Ibaraki, Japan \\ E-mail: suzuki.keita.wu@alumni.tsukuba.ac.jp \\ ${ }^{2}$ Department of Physical Therapy, Faculty of Health Sciences, Tsukuba International University, 6-8-33 Manabe, Tsuchiura, Ibaraki, Japan \\ ${ }^{3}$ Department of Business Management, Faculty of Modern Life, Teikyo Heisei University \\ 4-21-2 Nakano, Nakano-ku, Tokyo, Japan \\ ${ }^{4}$ Faculty of Health and Sport Science, University of Tsukuba, 1-1-1 Tennodai, Tsukuba, Ibaraki, Japan \\ [Received August 6, 2019; Accepted March 22, 2020; Publication online April 6, 2020]
}

\begin{abstract}
The present study aimed to determine the mechanisms of mild cervical injuries caused by tackling in a rugby union. This study enrolled 137 male players from a Japanese collegiate rugby union club during the 2009-2013 seasons. Twenty-nine (53.7\%) of 54 incidents leading to mild cervical injury were identified from match video records and injury data that were reported under the definition of medical attention. In addition, all tackles by players in the same match in which they sustained cervical injury were extracted as a control cohort. All tackles were coded according to eleven characteristics of three tackle phases. Twenty-one tackles were the main events leading to mild cervical injury. The likelihood of tacklerassociated mild cervical injuries was significantly higher when tacklers had no time to face forward at the offside line before tackle situations, tackles with incorrect tackler head positions, and not using arms after initial contact. These results suggest that further investigation is needed to determine specific tackling characteristics considering the three tackle phases and their combined effects.
\end{abstract}

Key Words: brachial plexopathy, cervical sprain, etiology, community rugby, tackle

\section{Introduction}

Rugby union is a popular collision sport played worldwide that is characterized by frequent contact between players. Of particular concern in contact situations is that tackles have the potential to cause serious head and cervical injuries (Fuller et al., 2010; Kemp et al., 2008; McIntosh et al., 2010a). Head and cervical injuries are far more common in rugby than in other sports (Brooks et al., 2005). The incidence of spinal cord injury is following a decreasing trend (Bohu et al., 2009; Brown et al., 2016; Gianotti et al., 2009), but mild cervical injuries such as cervical sprains and brachial plexopathy remain problematic (Holtzhausen et al., 2006). Cervical facet joint pain $(42.2 \%)$ and brachial plexopathy $(14.4 \%)$ are frequently sustained in amateur rugby union (Swain et al., 2010). By contrast, professional players appear to be more likely to sustain brachial plexus injuries, including nerve root damage, which accounts for $38.4 \%$ of all cervical injuries (Fuller et al., 2007a). Swain et al.
(2010) reported the incidence of cervical injury in amateur rugby union teams in Australia. In that study, the incidence of cervical injury due to match play was $6.0 / 1000$ player-hours $(\mathrm{PH})(95 \%$ confidence interval [CI], 4.8-7.5), defined by both time loss and injury requiring medical attention. The incidence of cervical injury which was calculated for both time loss and injury requiring medical attention ranged from 0.5 to 9.2 injuries/1000 PH (95\% CI, 0.1-26.8) across three studies of professional rugby union players (Holtzhausen et al., 2006; Hughes and Fricker, 1994; Targett, 1998). The incidence of cervical injury in professional rugby union players has been described in many reports, but little is known about this topic in amateur rugby union players (Swain et al., 2010).

Contact situations, especially tackling for rugby union players, frequently cause cervical injuries (Fuller et al., 2007a; McIntosh et al., 2010a; Swain et al., 2010). Previous studies characterizing injuries have used injury records reported by team medical staff (Fuller et al., 2007a; McIntosh et al., 2010a; Swain et 
al., 2010). Video analysis can be used to clarify the characteristics of tackle situations that lead to injury in rugby union (Burger et al., 2016; McIntosh et al., 2010b; Quarrie and Hopkins, 2008). Therefore, video records are more useful for describing the circumstances leading to injuries than injury records reported by team medical staff, which are subject to recall bias (Brooks et al., 2005). However, little has been published about tackle situations leading to cervical injuries characterized based on video analysis in rugby union. Tackling situations that lead to mild cervical injury need to be clarified to develop interventions. This study aimed to elucidate the mechanisms of mild cervical injuries caused by tackling in rugby union.

\section{Methods}

\subsection{Participants}

We recruited 340 players from a Japanese collegiate rugby union team for this study. We analyzed all matches between the 2009-2010 and the 2013-2014 playing seasons. Among the players, 203 played more than one full season. The Ethics Committee of the Faculty of Health and Sport Science at the University of Tsukuba approved the present study (Reference number 27-88), and all players provided written informed consent before participating.

\subsection{Cervical injury data}

Mild cervical injuries were reported following the consensus statement on injury surveillance studies for rugby union (Fuller et al., 2007b). A "time-loss" (TL) injury is defined as damage that prevents a player from fully participating in the next rugby training session or match play typically planned for that day for a period of greater than $24 \mathrm{~h}$ from midnight at the end of the day the injury was sustained and a "medical attention" (MA) injury is defined as damage requiring medical attention by any team of medical personnel regardless of whether or not the player lost time (Fuller et al., 2007b). We included both MA and TL injuries in the injury data because they were more prevalent than TL injuries only, and thus a larger sample was obtainable. The cases in which players suffered neck pains, but TL did not occur, can be extracted by including MA injuries in the injury data. All players who sustained mild cervical spine injuries were clinically diagnosed by a team doctor. In the present study, a mild cervical spine injury is defined as cervical trauma other than fatal and non-fatal catastrophic cervical spine injuries, such as brachial plexopathy or cervical sprains/whiplash injury.

\subsection{Video analysis}

Video analysis consisted of four steps. We initially identified mild cervical injury events based on surveillance data, and then selected appropriate scenes from reviews of match video records. Secondly, all incidents leading to a cervical injury were coded in accordance with game situations such as phase of play, playing position, period in the match, and playing area at the time of the injury. Thirdly, all tackles in a match made by an injured player before sustaining mild cervical injury were extracted and included in the video analysis as controls. We defined "tackle" as any contact event where one or more tacklers attempted to stop the ball carrier, regardless of whether the ball carrier was brought to ground (Fuller et al., 2010). However, tackles were excluded from analysis when precise tackling situations could not be identified or when poor video quality prevented coding. The first author (KS) coded all tackling events using 10 factors in three tackle phases (Table 1) (Burger et al., 2017; Fuller et al., 2010; Hendricks et al., 2014; Quarrie and Hopkins, 2008; Shimasaki et al., 2017). The three phases in tackling situations are as follows: pre-contact ( $0.5 \mathrm{~s}$ preceding initial contact, Figure 1AB), contact (the moment of contact, Figure 1C), and post-contact (until tackle outcomes are identified, Figure 1D-F) (Fuller et al., 2010). Tackling factors were separately analyzed to establish associations between each tackle phase with mild cervical injuries.

We calculated kappa statistics ( $\kappa)$ to test the interrater reliability of two raters for each coded tackling characteristic. Twenty-five tackling situations were randomly selected from those that led to cervical injuries and controls (Kundel and Polansky, 2003). Moderate, fair to good, and excellent agreement between repeated measures were taken as having $\kappa$ ranges of $0.41-0.60,0.61-0.80$, and $0.81-0.99$, respectively (Kirkwood and Sterne, 2003). The $\kappa$ values for interrater reliability were 0.83 (pre-contact), 0.76 (contact), and 0.92 (post-contact).

\subsection{Statistical analysis}

The incidence of cervical injury during matches 
Table 1 Tackling characteristics and their descriptions

\begin{tabular}{|c|c|}
\hline Tackling characteristics & Descriptions \\
\hline \multicolumn{2}{|l|}{ Pre-contact phase } \\
\hline \multicolumn{2}{|c|}{ Enough time to face forward at the offside line } \\
\hline Yes & $\begin{array}{l}\text { Tackler has } 2.0 \text { seconds to face forward at own offside line prior to when the ball leaves a scrum, } \\
\text { lineout, maul or ruck (Shimasaki et al., 2017)* }\end{array}$ \\
\hline No & Tackler don't have enough time to face forward at own offside line \\
\hline \multicolumn{2}{|c|}{ Tackler moves toward try or goal line } \\
\hline Same direction & Tackler chasing ball-carrier toward own goal line \\
\hline Opposite direction & Tackler and ball-carrier moving head on toward each other \\
\hline \multicolumn{2}{|c|}{ Tackler moves toward the touchline } \\
\hline Same direction & Tackler moving in response to ball-carrier in the same direction \\
\hline Opposite direction & Tackler moving in response to ball-carrier in the opposite direction \\
\hline \multicolumn{2}{|l|}{ Ball-carrier speed } \\
\hline Stationary & Stationary or walking \\
\hline Jog & Jogging \\
\hline Sprint & Running or sprinting \\
\hline \multicolumn{2}{|l|}{ Tackler speed } \\
\hline Stationary & Stationary or walking \\
\hline Jog & Jogging \\
\hline Sprint & Running or sprinting \\
\hline \multicolumn{2}{|l|}{ Contact phase } \\
\hline \multicolumn{2}{|c|}{ Ball-carrier body region struck } \\
\hline Head/neck & Above the shoulder with any connection with the head/neck \\
\hline Chest region & From ball-carrier's shoulder level to the arm pit level, including the arms \\
\hline Trunk region & Above the ball-carrier's hip level to the arm pit level \\
\hline Lower leg region & Area between ball-carrier's hips and toes \\
\hline \multicolumn{2}{|l|}{ Tackler body region struck } \\
\hline Head/neck & Tackler contacts the ball-carrier with the head/neck \\
\hline Shoulder & Tackler contacts the ball-carrier with the shoulder \\
\hline Chest & Tackler contacts the ball-carrier with the chest \\
\hline Arm & Tackler contacts the ball-carrier with the arm \\
\hline Hand & Tackler contacts the ball-carrier with the hand \\
\hline \multicolumn{2}{|l|}{ Correct tackler head position } \\
\hline Yes & Tackler's head is positioned correct side, where tackler's head don't contact the ball-carrier directly. \\
\hline No & Tackler's head is positioned incorrect side, where tackler's head contacts the ball-carrier directly. \\
\hline \multicolumn{2}{|r|}{ 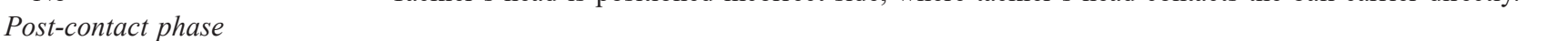 } \\
\hline \multicolumn{2}{|l|}{ Arm usage } \\
\hline Yes & Tackler uses arm after the initial contact to pull or hold ball-carrier \\
\hline No & Tackler does not use his hand or arm \\
\hline \multicolumn{2}{|l|}{ Tackle result } \\
\hline Success & $\begin{array}{l}\text { After contact, the tackler prevents the ball-carrier and ball progressing towards his try-line and does } \\
\text { not concede a penalty }\end{array}$ \\
\hline Failure & $\begin{array}{l}\text { When the ball-carrier was able to offload the ball, or break an attempted tackle, or form a maul, or } \\
\text { an infringement was committed, or when a try was scored }\end{array}$ \\
\hline
\end{tabular}

* We set the enough time to face forward to 2.0 seconds because it takes usually more than 2.0 seconds until the ball gets out from breakdowns.

was calculated as the number of cervical injuries per $1000 \mathrm{PH}$ with $95 \%$ CI. The incidence was calculated from each game situation as phase of play, playing position, period in the match, and playing area. Significant differences $(\mathrm{p}<.05)$ in the numbers of injuries among each game situation as the phase of play, playing position, period in the match, and playing area were assessed using $\chi^{2}$ tests. Significant differences in values for incidence were assumed if the $95 \%$ CI did not overlap (Brooks et al., 2005).

Logistic regression analysis proceeded using SPSS version 24.0 (IBM Japan Inc., Tokyo, Japan) after descriptive statistics (frequency, \%). Descriptive statistics were determined to exclude tackling characteristics that had a frequency of $0 \%$ from the independent variables of logistic regression analyses. The adjusted odds ratios (OR) and 95\% CI were determined by multiple logistic regression analysis for each tackle 

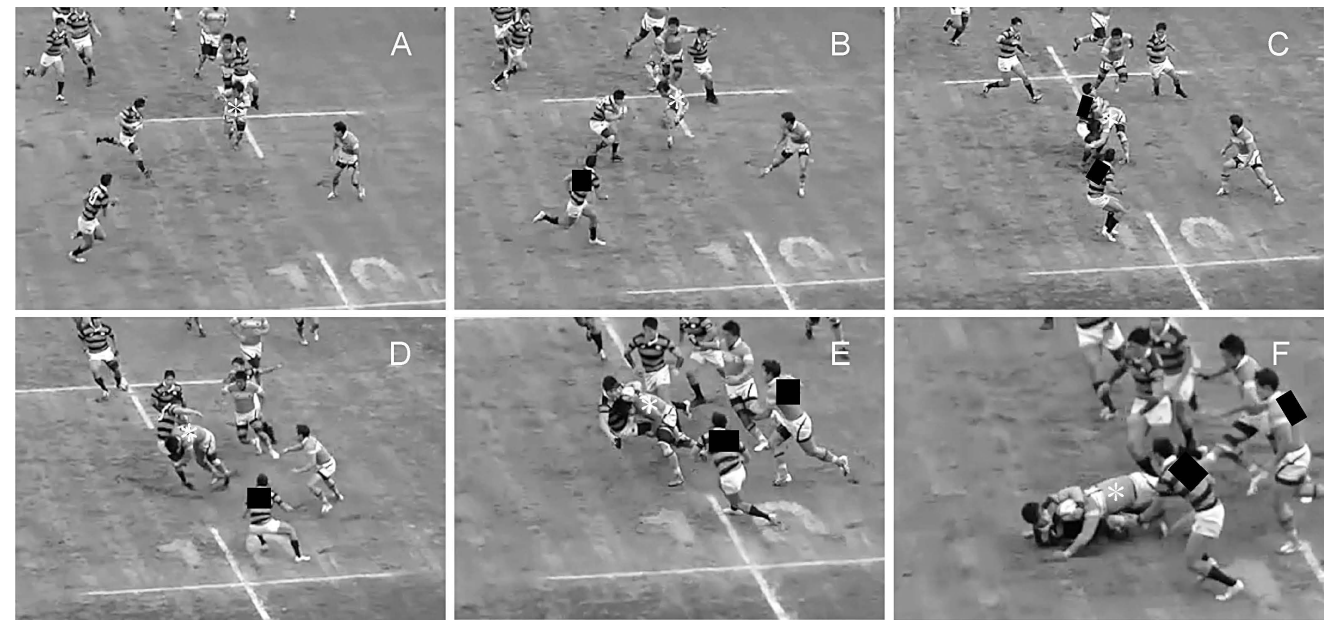

Figure 1 Tackle phase. (A-B) Tackler approached the ball-carrier (the pre-contact phase). (C) Tackler contacted the ball-carrier (the contact phase). (D-F) After tackler made a contact and the tackle result was identified. (the post-contact phase). *Tackler.

phase or tackle outcome $(\mathrm{p}<.05)$. Factors with apparently low associations with the occurrence of mild cervical injuries were initially excluded using $\chi^{2}$ tests with SAS version 9.4 (SAS Institute Japan) (Cramer's $\mathrm{V}<0.10, \mathrm{p}<.05)$. We then incorporated selective tackling characteristics into multiple logistic regression analysis based on the results of the $\chi^{2}$ tests (Cramer's $\mathrm{V} \geq 0.10, \mathrm{p}<.05$ ). For independent variables, we selected tackling characteristics with the highest frequency as the reference category. For the dependent variable, we selected "no mild cervical injury" as the base category. If the OR of a specific tackling characteristic was $>1.0$ or $<1.0$, a mild cervical injury was more and less likely to occur, respectively, compared with the reference category.

\section{Results}

A total of 340 players participated in 225 matches during five seasons, and the total exposure time was 4,500 player-hours. Among 54 cervical injuries sustained during matches, 47 (87.0\%) instances of brachial plexopathy and 7 (13.0\%) cervical sprains/whiplash injuries were sustained by 36 players over the five seasons. The overall incidence of cervical injury was 12.0 injuries $/ 1000 \mathrm{PH}$ (95\% CI, 9.1-15.6). Twentynine $(53.7 \%)$ cervical injury situations were identified from match video records.

\subsection{Game situations}

Twenty-one cervical injuries were caused by tack-
Table 2 Game situations leading to cervical injuries

\begin{tabular}{lcc}
\hline & $\mathrm{n}(\%)$ & $\begin{array}{c}\text { Incidence } \\
(95 \% \text { CI })\end{array}$ \\
\hline $\begin{array}{l}\text { Phase of play* } \\
\text { Tackling }\end{array}$ & 29 & \\
Tackled & $21(72.4)$ & $4.7(2.9-7.1)$ \\
Maul & $1(3.4)$ & $0.2(0.0-1.2)$ \\
Ruck & 0 & - \\
Lineout & $2(6.9)$ & $0.2(0.0-1.2)$ \\
Scrum & 0 & - \\
Collision & $3(10.3)$ & $0.7(0.1-2.0)$ \\
Playing position* & $2(6.9)$ & $0.4(0.1-1.6)$ \\
Forwards & & \\
Backs & $23(79.3)$ & $5.1(3.3-7.7)$ \\
Period in the match (mins) & $6(20.7)$ & $1.3(0.5-3.0)$ \\
$\quad 0-20$ & $11(37.9)$ & $2.4(1.2-4.4)$ \\
20-40 & $7(24.1)$ & $1.6(0.6-3.2)$ \\
40-60 & $5(17.2)$ & $1.1(0.4-2.6)$ \\
60-80+ & $6(20.7)$ & $1.3(0.5-3.0)$ \\
Playing area* & & \\
Own goal line to 22m line & $9(31.0)$ & $2.0(0.9-3.8)$ \\
Own 22m line to halfway line & $12(41.4)$ & $2.7(1.4-4.7)$ \\
Half way line to opposite 22m line & $7(24.1)$ & $1.6(0.6-3.2)$ \\
Opposite 22m line to goal line & $1(3.4)$ & $0.2(0.0-1.2)$ \\
\hline
\end{tabular}

Note. CI: confidence intervals

*: Statistical significance based on $\chi^{2}$ test $(\mathrm{p}<.05)$

ling (Table 2). Tacklers had the highest incidence of cervical injury compared with other contact plays (Table 2). Significantly more cervical injuries were sustained by forward players than back players (Table 2). Significantly more cervical injuries occurred in their own field between the $22 \mathrm{~m}$ line and halfway line than between the opposite $22 \mathrm{~m}$ line and goal line. However, no other playing areas were statis- 
tically significant within this group (Table 2).

\subsection{Multiple logistic regression outcomes}

A total of 102 tackles were identified as controls. From the results of descriptive statistics, characteristics with a frequency of $0 \%$ were excluded from logistic regression analysis (Table 3-5). We analyzed 120 tackles, including 20 that led to mild cervical injuries and 100 that did not result in any injuries.

\subsubsection{Pre-contact phase}

We included sufficient time to face forward at the offside line and tackler speed into multinomial logistic regression analysis based on the results of the $\chi^{2}$ tests. The risk of cervical injury was increased when the tackler had insufficient time to face forward at the offside line $(\mathrm{OR}=3.27 ; 95 \% \mathrm{CI}, 1.17-9.16 ; \mathrm{p}=.024)$

(Table 6).

\subsubsection{Contact phase}

We included where on the body contact was made

Table 3 The frequency distribution for mild cervical injury and effect size in pre-contact phase

\begin{tabular}{|c|c|c|c|c|c|}
\hline \multirow[t]{2}{*}{$\begin{array}{l}\text { Categorical } \\
\text { variables }\end{array}$} & $\begin{array}{l}\text { Cervical } \\
\text { injury } \\
(n=20)\end{array}$ & $\begin{array}{c}\text { No } \\
\text { injury } \\
(\mathrm{n}=100) \\
\end{array}$ & \multirow[t]{2}{*}{$\begin{array}{l}\text { Fisher's } \\
\chi^{2} \text { test }\end{array}$} & \multirow[t]{2}{*}{$\mathrm{p}$} & \multirow[t]{2}{*}{$\begin{array}{c}\text { Cramer's } \\
\text { V }\end{array}$} \\
\hline & n (\%) & n $(\%)$ & & & \\
\hline $\begin{array}{l}\text { Enough time to face } \\
\text { forward at the off- } \\
\text { side line }\end{array}$ & & & 6.10 & .020 & 0.22 \\
\hline Yes & $8(40.0)$ & $69(69.0)$ & & & \\
\hline No & $12(60.0)$ & $31(31.0)$ & & & \\
\hline $\begin{array}{l}\text { Tackler moves toward } \\
\text { try or goal line }\end{array}$ & & & 0.10 & .747 & 0.03 \\
\hline Same direction & $3(15.0)$ & $18(18.0)$ & & & \\
\hline Opposite direction & $17(85.0)$ & $82(82.0)$ & & & \\
\hline $\begin{array}{l}\text { Tackler moves } \\
\text { toward the touchline }\end{array}$ & & & 1.82 & .178 & 0.12 \\
\hline Same direction & $14(70.0)$ & $83(83.0)$ & & & \\
\hline Opposite direction & $6(30.0)$ & $17(17.0)$ & & & \\
\hline Speed of ball-carrier & & & 4.84 & .089 & 0.20 \\
\hline Sprint & $16(80.0)$ & $54(54.0)$ & & & \\
\hline Jog & $4(20.0)$ & $42(42.0)$ & & & \\
\hline Stationary & 0 & $4(4.0)$ & & & \\
\hline Speed of tackler & & & 8.93 & .012 & 0.27 \\
\hline Sprint & $4(20.0)$ & $20(20.0)$ & & & \\
\hline Jog & $11(55.0)$ & $75(75.0)$ & & & \\
\hline Stationary & $5(25.0)$ & $5(5.0)$ & & & \\
\hline
\end{tabular}

Statistical significance was set at $\mathrm{p}<.05$. Effect size by Cramer' $\mathrm{V}$ of $0.10-0.30,0.30-0.50$, and $>0.50$ were considered small, moderate, and large, respectively. to the ball carrier and tackler, as well as correct tackler head position into multinomial logistic regression analyses based on the results of the $\chi^{2}$ tests. The probability of concussion for tacklers was significantly higher during tackles with an incorrect head position $(\mathrm{OR}=4.85 ; 95 \% \mathrm{CI}, 1.17-20.12 ; \mathrm{p}=.030)$, compared to a correct head position (Table 6).

Table 4 The frequency distribution for mild cervical injury and effect size in contact phase

\begin{tabular}{lccccc}
\hline \multicolumn{1}{c}{$\begin{array}{c}\text { Categorical } \\
\text { variables }\end{array}$} & $\begin{array}{c}\text { Cervical } \\
\text { injury } \\
(\mathrm{n}=20)\end{array}$ & $\begin{array}{c}\text { No } \\
\text { injury } \\
(\mathrm{n}=100)\end{array}$ & $\begin{array}{c}\text { Fisher's } \\
\chi^{2} \text { test }\end{array}$ & $\mathrm{p}$ & $\begin{array}{c}\text { Cramer's } \\
\text { V }\end{array}$ \\
\cline { 2 - 3 } & $\mathrm{n}(\%)$ & $\mathrm{n}(\%)$ & & & \\
\hline $\begin{array}{l}\text { Ball-carrier body } \\
\text { region struck }\end{array}$ & & & 24.35 & $<.001$ & 0.45 \\
$\quad$ Head/neck & 0 & $6(6.0)$ & & & \\
Chest region & $2(10.0)$ & $55(55.0)$ & & & \\
Trunk region & $17(85.0)$ & $27(27.0)$ & & & \\
Lower leg region & $1(5.0)$ & $12(12.0)$ & & & \\
Tackler body region & & & 24.12 & $<.001$ & 0.45 \\
struck & & & & \\
Head/neck & $8(40.0)$ & $6(6.0)$ & & & \\
Shoulder & $11(55.0)$ & $54(54.0)$ & & & \\
Chest & 0 & $17(17.0)$ & & & \\
Arm & 0 & $20(20.0)$ & & & \\
Hand & $1(5.0)$ & $3(3.0)$ & & & \\
Correct tackler head & & & 10.82 & .001 & 0.30 \\
position & & & & \\
Yes & $6(30.0)$ & $69(69.0)$ & & & \\
No & $14(70.0)$ & $31(31.0)$ & & & \\
\hline
\end{tabular}

Statistical significance was set at $\mathrm{p}<.05$. Effect size by Cramer' $\mathrm{V}$ of $0.10-0.30,0.30-0.50$, and $>0.50$ were considered small, moderate, and large, respectively.

Table 5 The frequency distribution for mild cervical injury and effect size in post-contact phase

\begin{tabular}{|c|c|c|c|c|c|}
\hline \multirow[t]{2}{*}{$\begin{array}{c}\text { Categorical } \\
\text { variables }\end{array}$} & $\begin{array}{c}\text { Cervical } \\
\text { injury } \\
(\mathrm{n}=20)\end{array}$ & $\begin{array}{c}\text { No } \\
\text { injury } \\
(\mathrm{n}=100)\end{array}$ & \multirow[t]{2}{*}{$\begin{array}{l}\text { Fisher's } \\
\chi^{2} \text { test }\end{array}$} & \multirow[t]{2}{*}{$\mathrm{p}$} & \multirow[t]{2}{*}{$\begin{array}{c}\text { Cramer's } \\
\text { V }\end{array}$} \\
\hline & n $(\%)$ & n $(\%)$ & & & \\
\hline Arm usage & & & 10.52 & .001 & 0.30 \\
\hline Yes & $12(60.0)$ & $89(89.0)$ & & & \\
\hline No & $8(40.0)$ & $11(11.0)$ & & & \\
\hline Tackle result & & & 5.81 & .016 & 0.22 \\
\hline Success & $13(65.0)$ & $87(87.0)$ & & & \\
\hline Failure & $7(35.0)$ & $13(13.0)$ & & & \\
\hline
\end{tabular}

Statistical significance was set at $\mathrm{p}<.05$. Effect size by Cramer' $\mathrm{V}$ of $0.10-0.30,0.30-0.50$, and $>0.50$ were considered small, moderate, and large, respectively. 
Table 6 Logistic regression for tackler injury events

\begin{tabular}{lcc}
\hline \multicolumn{1}{c}{ Extracting factors } & $\begin{array}{c}\text { Adjusted OR } \\
(95 \% \mathrm{CI})\end{array}$ & $\mathrm{p}$ \\
\hline $\begin{array}{c}\text { Pre-contact phase } \\
\text { Enough time to face forward at the }\end{array}$ & Reference & \\
offside line (Yes) & $3.27(1.17-9.16)$ & .024 \\
No & Reference & \\
Tackler speed (Sprint) & $4.31(0.79-23.60)$ & .092 \\
Stationary & $0.66(0.18-2.37)$ & .524 \\
Jog & Reference & \\
Contact phase & & \\
Ball-carrier body region struck & $1.09(0.07-17.28)$ & .950 \\
(Lower leg region) & $7.59(0.70-81.94)$ & .095 \\
Chest region & Reference & \\
Trunk region & $2.06(0.41-10.34)$ & .381 \\
Tackler body region struck (Shoulder) & $2.08(0.16-27.50)$ & .580 \\
Head/neck & Reference & \\
Hand & $4.85(1.17-20.12)$ & .030 \\
Correct tackler head position (Yes) & & \\
No & Reference & \\
Post-contact phase* & $5.03(1.69-15.01)$ & .004 \\
Arm usage (Yes) & & \\
No & &
\end{tabular}

Note. OR: odds ratio; CI: confidence intervals

* We did not simultaneously include arm usage and tackle result in logistic regression analyses because these characteristics were closely associated (Cramer's V=0.91).

\subsubsection{Post-contact phase}

We did not simultaneously include arm usage and tackle result in logistic regression analyses because these characteristics were closely associated (Cramer's $\mathrm{V}=0.91$ ). Therefore, we incorporated only arm usage into binomial logistic regression analysis. Tacklers were significantly more likely to sustain cervical injuries when they did not use their arms after initial contact $(\mathrm{OR}=5.03 ; 95 \% \mathrm{CI}, 1.69-15.01 ; \mathrm{p}=.004)$, compared with when they did (Table 6).

\section{Discussion}

This study is the first to analyze the characteristics of events that lead to mild cervical injuries in a rugby union based on injury data and video records of matches. With regard to tackling characteristics leading to mild cervical injuries in particular, the results showed several characteristics in the contact phase and the post-contact phase that were in line with previous studies of concussion events, but revealed a different characteristic in the pre-contact phase.

\subsection{Incidence rate and game situations}

Previous studies indicated a cervical injury incidence of 0.5-9.2/1000 PH (Fuller et al., 2007a; Holtzhausen et al., 2006; Hughes and Fricker, 1994; Targett, 1998) among professional rugby union players and of 6.0/1000 PH among amateur rugby union players (Swain et al., 2010). The incidence of cervical injuries was higher in the present study than in previous studies of professional and amateur rugby union players.

Tacklers in this study sustained the greatest number of mild cervical injuries. This finding is in line with a previous study of amateur rugby union (Swain et al., 2010). Tackle situations have the greatest propensity to cause all types of injuries for both tacklers and the ball-carriers across all levels of play (Viviers et al., 2018). Recent video findings have shown an increased incidence of tackle-related injuries in rugby union (Burger et al., 2017; Cross et al., 2019; Fuller et al., 2010; Quarrie and Hopkins, 2008; Suzuki et al., 2019; Tierney et al., 2018; Tucker et al., 2017). However, tackling characteristics associated with mild cervical injuries based on video analysis have not been studied in detail. Furthermore, characteristics associated with tackler-related cervical injuries should be clarified.

We found that forwards were more likely to sustain mild cervical injuries than backs. This result concurs with previous findings (Swain et al., 2010). Forwards are more likely to be exposed to forward-specific contacts, such as scrums and mauls, than other than tackles, and thus might have accumulated more neck damage than backs. In addition, a history of brachial plexopathy increases risk of future sustaining subsequent brachial plexopathy (Kawasaki et al., 2015). Forwards are more likely than backs to sustain mild cervical injuries (Swain et al., 2010), thus, forwards might sustain more recurrent cervical injuries.

\subsection{Tackling characteristics related to mild cervi- cal injuries}

We identified tackling characteristics associated with the occurrence of tackler-related mild cervical injuries. The likelihood of tackler-associated mild cervical injuries was significantly higher when the tackler had insufficient time to face forward at the offside line, tackled with an incorrect head position, and did not use their arms. 


\subsubsection{Pre-contact phase}

The probability of a cervical injury increased when the tackler did not have sufficient time to face forward at the offside line. This finding is not shown in previous studies on tackling. The propensity for the tackler being unable to identify ball-carrier motion might be increased in this situation. Moreover, being unable to follow such motion before contact caused difficulties for tacklers to implement the appropriate actions when making initial contact, such as where to place their own head relative to the ball-carrier, which in turn, led to an increased risk of tackler-related cervical injuries. In addition, "identify/track ball-carrier onto shoulder" is associated with a lower propensity of a resulting head injury assessment for tacklers at the professional level (Tierney et al., 2018). In the present study, our finding was analyzed for the first time, it was extracted as a characteristic different from previous studies, but similar situations were also extracted in tackler-related concussions. Our research did not reveal the difference between whether concussion or mild cervical injury occurred, so further investigation will require. Our findings suggest that the incidence of tackler-related injuries increases when tacklers do not have enough time to face forward at the offside line to identify the ball-carrier.

\subsubsection{Contact phase}

Tackling with an incorrect head position increased the likelihood of tackler-related cervical injuries. This finding is in line with that of a previous study (Sobue et al., 2018; Suzuki et al., 2020). Tanabe et al. analyzed the kinematic aspects of tackles with the incorrect head position in laboratory conditions (Tanabe et al., 2019). As a result, in a tackle with the incorrect head position, the neck bending angle to the side of the impacted shoulder was 7 degrees greater compared to a shoulder tackle. During real-match situations, the neck bending ipsilateral to the impacted shoulder might be greater in comparison to the laboratory setting. Thus, a strong load is applied to the neck, which might lead to the traction of brachial plexus (i.e. the mechanism of brachial plexopathy) or the eccentric muscle contraction (i.e. the mechanism of cervical sprains) (Chang and Bosco, 2006). For the prevention of tackler-related mild cervical injury, therefore, tacklers should place behind or to one side of the ballcarrier according to the tackle direction.

\subsubsection{Post-contact phase}

The likelihood of tackler-related cervical injuries increased when tacklers did not use an arm after initial contact. This result concurs with previous findings of tackler-related concussion (Suzuki et al., 2019). In addition, Hendricks et al. (2014) reported that not using the arms increased the probability of tackle failure. Therefore, arm usage after initial contact is important for both injury prevention and tackle outcomes.

\subsection{Limitations}

Although the present study uncovered important information that will help to prevent tackler-related mild cervical injuries, several limitations should be addressed. Our results were based on a single collegiate rugby union team. Therefore, caution should be applied when generalizing our findings, even at the same playing level. We consider that further investigation is required to accumulate data about tackling characteristics related to mild cervical injuries at the collegiate or amateur level. We did not analyze contextual factors, such as match status at the time of tackle. These factors might also be associated with mild cervical injuries sustained by tacklers. Future studies will require a comprehensive analysis of both tackling characteristics and contextual factors related to mild cervical injuries.

\section{Conclusions}

We clarified the characteristics of cervical injuries sustained by collegiate rugby union players caused by tackling based on findings of match video records. We found that tacklers in collegiate rugby union were at higher risk of non-catastrophic cervical injury. Tackles leading to cervical injuries involved various factors associated with the three tackle phases. The likelihood of tackler-related mild cervical injuries was significantly higher when tacklers had no time to face forward at the offside line before tackle situations, initiating tackles with an incorrect head position, and not using an arm after initial contact. Our findings suggest that further investigation is needed to define each tackling characteristic from the viewpoint of the three tackle phases, as well as the combined effects of some tackling characteristics. 


\section{Conflict of Interest}

The authors declare no conflict of interest associated with this work.

\section{Acknowledgments}

The author would like to acknowledge the players of the University of Tsukuba Rugby Football Club for their willing participation in this study. The contribution made by the medical staff at the University of Tsukuba Rugby Football Club in recording match injuries is also acknowledged. The author would also like to thank the contributions of Yasunari Takagi for identifying the scenes of cervical injury.

\section{References}

Bohu, Y., Julia, M., Bagate, C., Peyrin, J. C., Colonna, J. P., Thoreux, P., and Pascal-Moussellard, H. (2009). Declining incidence of catastrophic cervical spine injuries in French rugby: 1996-2006. Am. J. Sports Med., 37: 319-323.

Brooks, J. H., Fuller, C. W., Kemp, S. P., and Reddin, D. B. (2005). Epidemiology of injuries in English professional rugby union: part 1 match injuries. Br. J. Sports Med., 39: 757-766.

Brown, J. C., Verhagen, E., Knol, D., Van Mechelen, W., and Lambert, M. I. (2016). The effectiveness of the nationwide BokSmart rugby injury prevention program on catastrophic injury rates. Scand. J. Med. Sci. Sports, 26: 221-225.

Burger, N., Lambert, M. I., Viljoen, W., Brown, J. C., Readhead, C., den Hollander, S., and Hendricks, S. (2017). Mechanisms and Factors Associated With Tackle-Related Injuries in South African Youth Rugby Union Players. Am. J. Sports Med., 45: 278-285.

Burger, N., Lambert, M. I., Viljoen, W., Brown, J. C., Readhead, C., and Hendricks, S. (2016). Tackle technique and tacklerelated injuries in high-level South African Rugby Union under-18 players: real-match video analysis. Br. J. Sports Med., 50: 932-938.

Chang, D. and Bosco, J. A. (2006). Cervical spine injuries in the athlete. Bull. NYU Hosp. Jt. Dis., 64: 119-129.

Cross, M. J., Tucker, R., Raftery, M., Hester, B., Williams, S., Stokes, K. A., Ranson, C., Mathema, P., and Kemp, S. (2019). Tackling concussion in professional rugby union: a case-control study of tackle-based risk factors and recommendations for primary prevention. Br. J. Sports Med., 53: 1021-1025.

Fuller, C. W., Ashton, T., Brooks, J. H. M., Cancea, R. J., Hall, J., and Kemp, S. P. T. (2010). Injury risks associated with tackling in rugby union. Br. J. Sports Med., 44: 159-167.

Fuller, C. W., Brooks, J. H., and Kemp, S. P. (2007a). Spinal injuries in professional rugby union: a prospective cohort study. Clin. J. Sport Med., 17: 10-16.

Fuller, C. W., Molloy, M. G., Bagate, C., Bahr, R., Brooks, J. H., Donson, H., Kemp, S. P., McCrory, P., McIntosh, A. S., Meeuwisse, W. H., Quarrie, K. L., Raftery, M., and Wiley, P. (2007b). Consensus statement on injury definitions and data collection procedures for studies of injuries in rugby union. Br. J. Sports Med., 41: 328-331.

Gianotti, S. M., Quarrie, K. L., and Hume, P. A. (2009). Evaluation of RugbySmart: a rugby union community injury prevention programme. J. Sci. Med. Sport, 12: 371-375.

Hendricks, S., Matthews, B., Roode, B., and Lambert, M. (2014).
Tackler characteristics associated with tackle performance in rugby union. Eur. J. Sport Sci, 14: 753-762.

Holtzhausen, L. J., Schwellnus, M. P., Jakoet, I., and Pretorius, A. L. (2006). The incidence and nature of injuries in South African rugby players in the rugby Super 12 competition. S. Afr. Med. J., 96: 1260-1265.

Hughes, D. C. and Fricker, P. A. (1994). A prospective survey of injuries to first-grade rugby union players. Clin. J. Sport Med., 4: 249-256.

Kawasaki, T., Ota, C., Yoneda, T., Maki, N., Urayama, S., Nagao, M., Nagayama, M., Kaketa, T., Takazawa, Y., and Kaneko, K. (2015). Incidence of Stingers in Young Rugby Players. Am. J. Sports Med., 43: 2809-2815.

Kemp, S. P., Hudson, Z., Brooks, J. H., and Fuller, C. W. (2008). The epidemiology of head injuries in English professional rugby union. Clin. J. Sport Med., 18: 227-234.

Kirkwood, B. and Sterne, J. (2003). Essential Medical Statistics. Blackwell science: Oxford.

Kundel, H. L. and Polansky, M. (2003). Measurement of observer agreement. Radiology, 228: 303-308.

McIntosh, A. S., McCrory, P., Finch, C. F., and Wolfe, R. (2010a). Head, face and neck injury in youth rugby: incidence and risk factors. Br. J. Sports Med., 44: 188-193.

McIntosh, A. S., Savage, T. N., McCrory, P., Frechede, B. O., and Wolfe, R. (2010b). Tackle characteristics and injury in a cross section of rugby union football. Med. Sci. Sports Exerc., 42: 977-984.

Quarrie, K. L. and Hopkins, W. G. (2008). Tackle injuries in professional Rugby Union. Am. J. Sports Med., 36: 1705-1716.

Shimasaki, T., Chiba, G., Furukawa, T., and Nakagawa, A. (2017). Change in Ball Continuity Situations in Breakdown in WorldClass Rugby_-Focusing on the Number of Players Involved and Time Required to Get the Ball out-. Football Sci., 14: 24-33.

Sobue, S., Kawasaki, T., Hasegawa, Y., Shiota, Y., Ota, C., Yoneda, T., Tahara, S., Maki, N., Matsuura, T., Sekiguchi, M., Itoigawa, Y., Tateishi, T., and Kaneko, K. (2018). Tackler's head position relative to the ball carrier is highly correlated with head and neck injuries in rugby. Br. J. Sports Med., 52: 353-358.

Suzuki, K., Nagai, S., Iwai, K., Furukawa, T., Mukai, N., Miyakawa, S., and Takemura, M. (2020). Characteristics and factors of concussion events for tacklers in collegiate rugby union. Scand. J. Med. Sci. Sports, 30: 185-192.

Suzuki, K., Nagai, S., Ogaki, R., Iwai, K., Furukawa, T., Miyakawa, S., and Takemura, M. (2019). Video analysis of tackling situations leading to concussion in collegiate rugby union. J. Phys. Fitness Sports Med., 8: 79-88.

Swain, M. S., Pollard, H. P., and Bonello, R. (2010). Incidence, severity, aetiology and type of neck injury in men's amateur rugby union: a prospective cohort study. Chiropr Osteopat, 18: 18.

Tanabe, Y., Kawasaki, T., Tanaka, H., Murakami, K., Nobuhara, K., Okuwaki, T., and Kaneko, K. (2019). The kinematics of 1-on-1 rugby tackling: a study using 3-dimensional motion analysis. J. Shoulder Elbow Surg., 28: 149-157.

Targett, S. G. (1998). Injuries in professional Rugby Union. Clin. J. Sport Med., 8: 280-285.

Tierney, G. J., Denvir, K., Farrell, G., and Simms, C. K. (2018). The effect of tackler technique on head injury assessment risk in elite rugby union. Med. Sci. Sports Exerc., 50: 603-608.

Tucker, R., Raftery, M., Kemp, S., Brown, J., Fuller, G., Hester, B., Cross, M., and Quarrie, K. L. (2017). Risk factors for head injury events in professional rugby union: a video analysis of 464 head injury events to inform proposed injury prevention strate- 
gies. Br. J. Sports Med., 51: 1152-1157.

Viviers, P. L., Viljoen, J. T., and Derman, W. (2018). A Review of a Decade of Rugby Union Injury Epidemiology: 2007-2017. Sports Health, 10: 223-227.

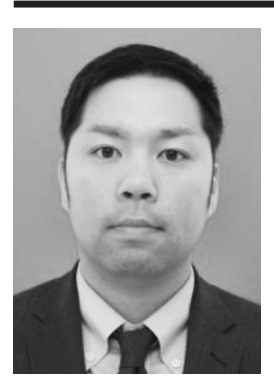

\section{Name:}

Keita Suzuki

Affiliation:

Center of Humanities and Sciences, Ibaraki Prefectural University of Health Sciences

\section{Address:}

4669-2 Ami, Inashiki, Ibaraki 300-0394, Japan

Brief Biographical History:

2015-current Center of Humanities and Sciences, Ibaraki Prefectural University of Health Sciences

2016-2019 Doctoral Course in Sports Medicine, Graduate School of Comprehensive Human Sciences, University of Tsukuba

\section{Main Works:}

-Suzuki, K., Nagai, S., Iwai, K., Furukawa, T., Mukai, N., Miyakawa, S., and Takemura, M. (2020). Characteristics and factors of concussion events for tacklers in collegiate rugby union. Scand. J. Med. Sci. Sports, 30: 185-192.

-Suzuki, K., Nagai, S., Ogaki, R., Iwai, K., Furukawa, T., Miyakawa, S., and Takemura, M. (2019). Video analysis of tackling situations leading to concussion in collegiate rugby union. J. Phys. Fitness Sports Med., 8: 79-88.

\section{Membership in Learned Societies:}

- Japanese Society of Clinical Sports Medicine

- Japanese Society of Physical Fitness and Sports Medicine

- Japanese Society for Athletic Training

-European College of Sport Science 